\section{Weapons potential}

\section{Defence lobby eyes antimatter}

THE US Air Force appears to be taking seriously a report from the Rand Corporation that antimatter might be used as a component of weapons systems. Antimatter packs a tremendous punch, equivalent to some 44 tons of TNT per milligram, when it annihilates with ordinary matter, but until particle physicists began to make and handle antimatter (particularly antiprotons) routinely, any thought of using the material was mere science fiction. But the report, commissioned from Rand, a non-profit US think-tank, by the US Air Force in 1983 and released last year, claims that problems facing the use of antimatter in rocket motors for reversing direction in Earth orbit, beam weapons and the pumping of X-ray lasers could be resolved within five years. Sufficient amounts of antimatter to be militarily "interesting" - some $10 \mathrm{mg}$ a year could be produced within another 15 years if the US government were prepared to spend between $\$ 5,000$ and 15,000 million on a development programme.

Basic research on antiproton trapping is already under way at laboratories such as the European Organization for Nuclear Research (CERN) near Geneva. The report says that interaction with basic science could push a military programme for- ward: "Our position is that the critical experimental work... is so rich with interest and so widespread in the area it intersects that researchers outside existing defense research (as well as those in it) should find it stimulating and an opportunity for creative invention". This interest leads to Rand's "reasonably confident prediction" that five years of research would resolve whether military applications are possible.

But could antimatter, currently produced in only miniscule amounts (some $10^{11}$ antiprotons per day, or $10^{-8}-10^{-7} \mathrm{mg}$ per year at CERN, for example) really be collected and used? According to Rand, the production and storage problems will be difficult and complex, and "there can be no confident assertion" that they will be solved. Many handling issues might be solved in experiments on normal matter (such as negative hydrogen ions that simulate the mass and charge of antiprotons) and others with present antiproton production technologies. Antiprotons could be held in static or dynamic electromagnetic traps (for example, Penning traps); at special sites in normal matter (for example in liquid helium bubbles); as spinpolarized antihydrogen; or as condensed antihydrogen in a cryogenic enclosure.

\title{
Computers thriving from NSF coffers
}

\section{Washington}

THE total value of research awards by the National Science Foundation (NSF) has increased substantially over the past four years, although some subjects have done much better than others (see below). The graph shows total awards made by each of the foundation's research directorates in constant dollars; retroactive adjustments have been made as necessary to take account of changes in jurisdiction, so that categories are consistent. Average award size by each directorate also increased over the same period.

All directorates' awards increased between 1982 and 1986 , but a fall between 1985 and 1986 is evident, caused in part by the effect of Gramm - Rudman budget cuts in the current fiscal year. Much the largest increase was for computer and information sciences and engineering ( 129 per cent after inflation over the four years). This largely reflects NSF's establishment of five supercomputer centres. The other increases were 45.3 per cent for engineering, 23 per cent for mathematics and physical sciences, 14.4 per cent for geosciences and 21 per cent for biological and social sciences.

The administration proposed an increase again in 1987 for NSF, but Congress may yet baulk at the idea (see Nature 322,
487; 1986). NSF's budget proposal for 1988 , now ready to go the Office of Management and Budget, will, according to director Erich Bloch, be "highly responsive" to the call of the Packard report ear-

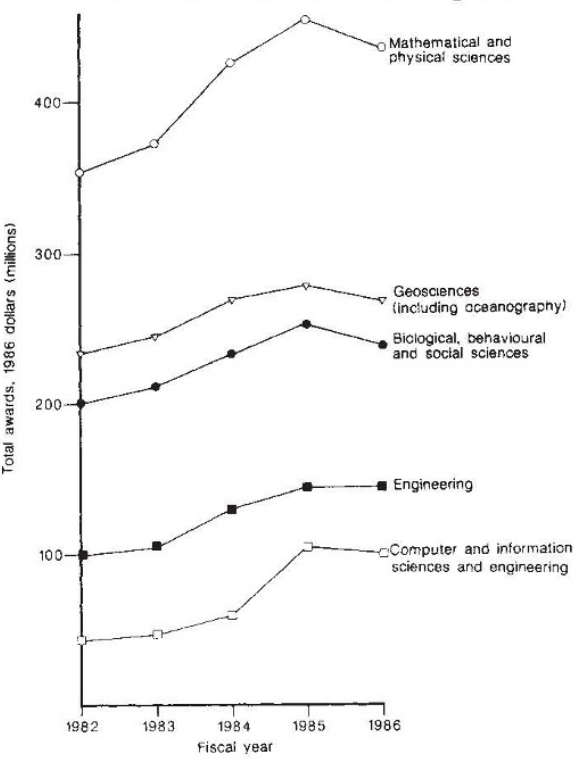

lier this year (Nature 321,$372 ; 1986$ ) for NSF to administer a $\$ 10,000$ million 10 year programme to improve university research facilities.
Antimatter has already been stored in minute quantities, and an experiment approved at CERN by a collaboration led by a Los Alamos group could lead to the storage of $10^{11}$ antiprotons per cubic centimetre. The main aim of this experiment is the collection and cooling of single antiprotons to measure their weight (do they fall upwards?), but the funding for this part of the experiment has not yet been raised. The rest of the experiment involves antiproton accumulation in a Penning bulk ion storage trap. The experiment has nothing to do with Rand's proposals, a spokesman points out.

Production of sufficient antiprotons to be useful, and the energy costs involved, may be the hardest problem facing weapons designers. Produced by colliding a proton beam to a target, at most one antiproton is collected per 100 incident protons, and this at the highest beam energy in use for the purpose $(120 \mathrm{GeV}$ at the Fermi National Accelerator Laboratory near Chicago). Taking into account the energy efficiency of accelerators, and assuming a "difficult near-term improvement" in antiproton collection technology, some $4 \mathrm{GW}$ of external power would be needed to produce the militarily useful amounts of $10 \mathrm{mg}$ of antiprotons a year, the report estimates. This is a huge and expensive power consumption but the gaseous diffusion plants for the separation of uranium isotopes once used in the manufacture of nuclear weapons consumed $6 \mathrm{GW}$. With the same parameters, antimatter production costs would reach $\$ 133$ million per $\mathrm{mg}$. "Some applications" could easily accommodate such costs, the report says.

Antimatter could be used for propulsion, power generation, beam weapons and "classified additional special weapons roles". In propulsion, for example, the annihilation of antihydrogen with hydrogen could produce effective exhaust velocities of $10 \mathrm{~km} \mathrm{~s}^{-1}$ to a major fraction of the speed of light. Propulsion missions otherwise more or less impossible because of weight of fuel (such as Earth orbit reversal), would become feasible if antimatter were used.

In power generation, antimatter could be used for orbital prime power "for engagement". Antimatter could also help in the design of lightweight beam weapon systems, be used as beams for "hard kills", or help produce the very short energy pulses required in pumping $\mathrm{X}$-ray lasers.

Understanding antimatter would be a "prudent" goal for the US Air Force and worth an investment of $\$ 1$ million on basic research as a preliminary study, and if that went well another $\$ 100$ million spent on a phase-A (pre-prototype production factory) study. The Air Force appears to have taken this recommendation seriously, and a research programme has begun.
Robert Walgate 